\title{
RECURSO DE PROTECCIÓN Y GARANTÍA CONSTITUCIONAL DEL DEBIDO PROCESO EN LOS PROCEDIMIENTOS SEGUIDOS POR LOS ESTABLECIMIENTOS EDUCACIONALES EN LA ADOPCIÓN DE SANCIONES DISCIPLINARIAS. ANÁLISIS DE JURISPRUDENCIA
}

\author{
ACTION FOR PROTECTION OF BASIC CONSTITUTIONAL RIGHTS \\ AND CONSTITUTIONAL GUARANTEE OF DUE PROCESS IN PRO- \\ CEDURES FOLLOWED BY EDUCATIONAL ESTABLISHMENTS IN \\ TAKING DISCIPLINARY MEASURES. ANALYSIS OF JURISPRUDENCE
}

\section{ARTURO MATTE IZQUIERDO*}

\begin{abstract}
RESUMEN: En el presente trabajo se expondrán los diferentes argumentos que han utilizado los Tribunales para sustentar cada una de estas posturas; y, asimismo, los diferentes elementos que a juicio de la jurisprudencia analizada deben estar presentes en los procedimientos sancionatorios utilizados por los establecimientos educacionales, y la forma en que éstos deben adecuarse a un debido proceso.
\end{abstract}

Palabras clave: Recurso de protección, debido proceso, artículo $19 \mathrm{~N}^{\circ} 3$ inciso $4^{\circ}$ de la Constitución Política de la República, establecimientos educacionales, sanciones disciplinarias adoptadas contra alumnos, procedimientos sancionatorios aplicados por establecimientos educacionales.

ABSTRACT: This work mentions various arguments used by courts in order to support each of these theories, and also reviews the different aspects that according to the analyzed jurisprudence should be present in punishing proceedings applied by educational establishments, with the aim to adequate them to a due process.

Key words: "Action for protection of basic constitutional rights" (recurso de protección), right to due process, article $19 \mathrm{~N}^{\circ} 3^{\circ}$ paragraph $4^{\circ}$ of Chilean Constitution, educational establishments, disciplinary measures against students, punishing proceedings of educational establishments.

\section{INTRODUCCIÓN}

Desde la creación del recurso de protección la garantía constitucional del debido proceso ha sido constantemente invocada por los alumnos sancionados por establecimientos educacionales, al momento de impugnar, mediante esta acción cautelar, dicha sanción disciplinaria.

\footnotetext{
* Licenciado en Ciencias Jurídicas de la Pontificia Universidad Católica de Chile, correo electrónico:
} arturomatte@gmail.com 
Como consecuencia de estos recursos de protección, la jurisprudencia se ha visto en la necesidad de pronunciarse respecto de la validez y aplicabilidad de la garantía constitucional del debido proceso frente a los procedimientos sancionatorios seguidos por los establecimientos educacionales. En este punto, nuestros Tribunales han sido erráticos al momento de definir un criterio único, y es posible advertir fallos que, en esta materia, declaran tanto la procedencia como la improcedencia de esta garantía constitucional.

Por su parte, aquella jurisprudencia que se ha declarado a favor de la aplicabilidad de la garantía del debido proceso, ha ido definiendo los elementos que deben estar presentes en los procedimientos sancionatorios utilizados por los establecimientos educacionales al momento de adoptar una sanción disciplinaria, y la forma en que estos deben adecuarse a un debido proceso.

En el presente trabajo se pretende hacer un estudio y un análisis acabado de la jurisprudencia existente sobre esta materia.

\section{JURISPRUDENCIA QUE SOSTIENE LA IMPROCEDENCIA DE LA GARANTÍA CONSTITUCIONAL DEL DEBIDO PROCESO EN LOS PROCEDIMIENTOS SANCIONATORIOS SEGUIDOS POR LOS ESTABLECIMIENTOS EDUCACIONALES}

Frente a las omisiones cometidas por los establecimientos educacionales en el procedimiento destinado a aplicar una sanción disciplinaria, existe una amplia jurisprudencia que sostiene que en estos casos la Constitución Política no autoriza amparar mediante el recurso de protección la garantía del debido proceso.

Para sostener lo anterior, nuestros Tribunales han esgrimido dos tipos de argumentación:

i) Por una parte, algunos fallos sostienen que, conforme al texto del artículo 20 de la Constitución Política, es claro que la garantía que protege el recurso de protección se refiere única y exclusivamente a que nadie puede ser juzgado por comisiones especiales, contenida en el inciso $4^{\circ}$ del numeral $3^{\circ}$ del artículo 19 , protección que no se extiende al inciso $5^{\circ}$ del mismo artículo que es el que hace referencia al debido proceso propiamente tal, al establecer que "toda sentencia de un órgano que ejerza jurisdicción debe fundarse en un proceso previo legalmente tramitado", señalando acto seguido que "corresponderá al legislador establecer siempre las garantías de un procedimiento y una investigación racionales y justos".

ii) Por otra parte otros fallos afirman que, aun cuando el recurso de protección sí ampara el inciso $5^{\circ}$ del artículo 19 No 3 de la Constitución, consideran, sin embargo, que para el caso de sanciones disciplinarias adoptadas por un establecimiento educacional esta garantía carece de protección constitucional por estimar que dichos actos sancionatorios no constituyen una función jurisdiccional, tal como lo ordena el texto constitucional. 
1) El Ámbito de ACCiÓn del RECURSO de PROTECCiÓN NO SE EXTIENDE A LA GARANTÍA DEL DEBIDO PROCESO CONTEMPLADO EN EL ARTÍCULO 19 No 3, INCISO $5^{\circ}$ DE LA CONSTITUCIÓN

Como se mencionó precedentemente, en algunas oportunidades nuestros Tribunales han sostenido que la garantía del debido proceso no se encuentra amparada por el recurso de protección, sino que este solo se limita a proteger el derecho a que nadie sea juzgado por comisiones especiales.

Así lo observó por primera vez el Ministro Carlos Cerda en Acevedo Molina, Raúl con Vicerrector Académico de la Universidad de Santiago (1984), en su voto de minoría del fallo de la Corte de Apelaciones de Santiago: "El recurso estima transgredido el derecho que a toda persona reconoce el $N^{o} 3$ del art. 19 de la Constitución, tanto en lo concerniente a la prohibición de ser juzgado por comisiones especiales, cuanto en lo que atañe a la seguridad de un racional y justo procedimiento. Efectivamente, en su inciso cuarto el ordinal tercero del art. 19 prescribe que 'Nadie puede ser juzgado por comisiones especiales, sino por el tribunal que le señala la ley...'. Mas en el libelo en estudio no se explica en qué consistiría esta infracción, desde que la alusión que a la falta del derecho de defensa alli se hace es del todo inatinente a la citada prerrogativa. La omisión consistente en no haberse emplazado al estudiante acusado, siendo de suma trascendencia para la valoración del mérito de las piezas investigatorias, no es idónea para legitimar una protección que, por esa falta, el art. 20 no concibe"1.

La misma opinión fue sostenida por la Corte Suprema en Manuel Enrique Torres Céspedes con Decano de la Facultad de Ingeniería de la Universidad Tecnológica Metropolitana (2002), al confirmar el fallo de primera instancia que rechazó el recurso de protección que se comenta: "Lo que se reprocha a la autoridad recurrida, en los breves argumentos esgrimidos en el libelo aludido, en resumidas cuentas, es la falta de un debido proceso administrativo, pero a ello se refiere el inciso quinto del artículo 19 de la Constitución Política del Estado, en una garantía que no está protegida por la presente vía cautelar, que, conforme al artículo 20 del mismo texto, únicamente presta protección al inciso cuarto de aquel precepto"2.

En esta misma línea, llama la atención las reflexiones realizadas por la Corte de Apelaciones de Punta Arenas en Christian Alex Salazar Allende con Universidad de Magallanes (1993). La Corte constató que "los vicios de procedimientos recién consignados llevan a estos sentenciadores a concluir que la resolución recurrida puede estimarse como arbitraria, puesto que se dictó en una investigación sumaria en el que no se formularon formalmente ni notificaron cargos en contra del recurrente, sino que este solo tuvo conocimiento de los cargos después de aplicada la sanción y habiendo expirado con creces el plazo para apelar, no teniendo acceso a la investigación misma, imposibilitando con ello su derecho a defensa y contraviniendo una elemental tramitación de una investigación sumaria ocasionándole un

\footnotetext{
${ }^{1}$ Acevedo Molina, Raúl con Vicerrector Académico de la Universidad de Santiago (1984), considerando $7^{\circ}$ del voto de minoría del fallo de la Corte de Apelaciones de Santiago.

2 Manuel Enrique Torres Céspedes con Decano de la Facultad de Ingeniería de la Universidad Tecnológica Metropolitana (2002), considerando $4^{\circ}$ del fallo de la Corte Suprema. Esta misma postura se recoge también en Torres Méndez, Angélica con Rector de la Universidad Regional El Libertador (Corte de Apelaciones de Valparaíso, 21 de noviembre de 2000, Rol No 591-2000 (recurso de protección), considerando $2^{\circ}$, confirmado por la Corte Suprema el 19 de diciembre de 2000, Rol No 4.772-2000).
} 
perjuicio al alumno". Sin embargo, no obstante esta reflexión y en concordancia con la jurisprudencia aquí analizada, la Corte rechazó el recurso de protección fundado, entre otras consideraciones, en que los vicios del procedimiento antes enumerados no estarían amparados dentro de los límites conceptuales de la garantía del artículo 19 No 3 inciso 4 , relativo a que nadie puede ser juzgado por comisiones especiales, sino que "se encontrarian comprendidos en el inciso $5^{\circ}$ del citado $N^{\circ} 3$ del artículo 19 de la Constitución Política del Estado el que no se encuentra amparado por el recurso de protección" 3 .

\section{2) LOS PROCEDIMIENTOS SANCIONATORIOS SEGUIDOS POR UN ESTABLECIMIENTO EDUCACIONAL NO CONSTITUYEN UNA FUNCIÓN JURISDICCIONAL.}

Respecto de esta segunda línea argumental utilizado por los Tribunales para descartar la aplicación de la garantía del debido proceso, destaca el fallo de Ibarra Catalán, Mario con Escuela de Arte de la Municipalidad de Valparaíso (1982), en donde, frente a la cancelación de la matrícula impugnada por los alumnos sancionados, la Corte de Apelaciones de Valparaíso desestimó que se haya afectado la garantía del debido proceso invocada por los recurrentes, y rechazó el recurso de protección fundado en que "el habérseles caducado las matrículas a los recurrentes por parte del órgano administrativo de la Escuela de Bellas Artes de Valparaiso, existiendo fundamentos reglamentarios suficientes para ello, no supone juzgamiento a tales alumnos en la forma como razona el $N^{\circ} 3$ del artículo 19 mencionado, ya que mediante dicho acto no está realizando una función jurisdiccional"4.

Un pronunciamiento más explícito tuvo sobre esta materia la Corte de Apelaciones de Temuco en Pedro Alberto Muñoz Betancur con Rector del Instituto Claret Teodoro Arranz San Juan (1996): "El debido proceso que la ley contempla como garantía constitucional en el artículo $19 N^{o} 3$ de la Constitución Politica de la República, no se acepta ni es procedente, porque tal garantía constitucional está referida al juzgamiento que corresponde a los tribunales de la República, que son los únicos que señala la ley para todos los habitantes del país, como queda aún más claro al expresar el inciso $4^{\circ}$ de dicha disposición constitucional que toda sentencia de un órgano que ejerza jurisdicción debe fundarse en un proceso previo legalmente tramitado. En las instituciones de orden privado, donde las partes o personas aceptan la reglamentación de las mismas, las decisiones de ellas, ya sea de tribunales, comisiones o directivas, conforme a sus reglamentos, no quedan comprendidos dentro de las garantías que protege el presente recurso según expresa el artículo 20 de la Carta Fundamental" 5 .

\footnotetext{
${ }^{3}$ Christian Alex Salazar Allende con Universidad de Magallanes (1993), considerandos $9^{\circ}$ y $13^{\circ}$ del fallo de la Corte de Apelaciones de Punta Arenas.

${ }^{4}$ Ibarra Catalán, Mario con Escuela de Arte de la Municipalidad de Valparaiso (1982), considerando $3^{\circ}$ del fallo de la Corte de Apelaciones de Valparaíso. Idéntica argumentación se utilizó también en Torres Méndez, Angélica con Rector de la Universidad Regional El Libertador, citado en la nota al pie de página número 2.

5 Pedro Alberto Muñoz Betancur con Rector del Instituto Claret Teodoro Arranz San Juan (1996), considerando $2^{\circ}$ del fallo de la Corte de Apelaciones de Temuco. Este considerando, sin embargo, fue eliminado por la Corte Suprema en su fallo confirmatorio.
} 
Idéntica apreciación tuvo recientemente la Corte de Apelaciones de Santiago en Valenzuela Muñoz Sonia Margarita y otros con Director del Colegio Anexo Benjamín Vicuña Mackenna y Alcalde de la Comuna de La Florida (2007), que al rechazar el recurso de protección sostuvo que "tampoco se divisa la infracción a la garantía de igual protección de la ley en el ejercicio de los derechos, especificamente infracción a los incisos $3^{\circ}$ y $4^{\circ}$ del número 3 del artículo 19 de la Constitución Política de la República, el ser juzgado por comisiones especiales y el correspondiente debido proceso, ya que los recurrentes no fueron objeto de un juicio o juzgamiento ni fueron objeto de una sentencia jurisdiccional, sino que todo se limitó a aplicarles una sanción administrativa impuesta por el Director del colegio, persona revestida con facultades legales y reglamentarias suficientes para ello, por lo que resulta artificioso invocar tal garantía en el caso de autos, atendido a que el número 3 del artículo 19 de la Carta Magna se refiere precisamente a un juzgamiento en juicio, situación que no ha ocurrido en el caso de autos" 6 .

Por su parte, en Manuel Jiménez Rojas con Rector Subrogante de la Universidad de Concepción (1998), la Corte de Apelaciones de Concepción hace una distinción que, aunque puede resultar confusa, se encuentra en la misma línea que la jurisprudencia aquí analizada. En este caso el recurrente interpuso un recurso de protección como consecuencia de que la Universidad de Concepción puso término al contrato de trabajo que tenía como profesor, por haber participado en la divulgación al interior de la Universidad de un documento difamatorio contra sus autoridades, profesores y alumnos, según se concluyó luego de una investigación interna. En lo que a la garantía del debido proceso se refiere, la Corte señaló que "el verbo rector de esta garantía radica en el vocablo juzgado, de manera que por esta vía solo puede impugnarse la conducta ejecutada por determinado órgano que realice una actividad de juzgamiento, esto es, un acto jurisdiccional, omitiendo el presupuesto de previo establecimiento legal". Hecha esta aclaración, la Corte rechazó el recurso de protección, indicando al respecto que "el derecho a defensa y el debido proceso a que se refiere la $3^{a}$ garantía constitucional, supone la existencia de una situación jurídica a la cual sea llamada cualquiera autoridad u organismo con potestad para dilucidarlo para sancionar a alguna de las partes o para imponerles un determinado criterio, pero no tiene lugar cuando la comisión u órgano respectivo no actúa como tribunal y la decisión no recae en un acto jurisdiccional sino contractual" 7 .

En esta misma línea se puede interpretar lo señalado por la Corte de Apelaciones de Temuco en Matías Ignacio Salcedo Pino con Establecimiento Educacional Instituto Claret de Temuco (2005) frente a la alegación del recurrente en cuanto a que el establecimiento educacional se arrogó "facultades que corresponden exclusivamente al Poder Judicial" y que "se habría transformado en una comisión especial al no respetar las garantías de

${ }^{6}$ Valenzuela Muñoz, Sonia Margarita y otros con Director del Colegio Anexo Benjamín Vicuña Mackenna y Alcalde de la Comuna de La Florida (2007), considerando $8^{\circ}$ del fallo de la Corte de Apelaciones de Santiago.

${ }^{7}$ Manuel Jiménez Rojas con Rector Subrogante de la Universidad de Concepción (1998), considerandos $4^{\circ}$ y $8^{\circ}$, del fallo de la Corte de Apelaciones de Concepción. 
un justo y debido proceso". Al respecto, señaló que "no se puede pretender que en la aplicación de sanciones de distintas entidades, haya de judicializarse tales actividades, sometiendo aquella aplicación a las reglas del debido proceso, sobre todo si se considera que en planteles educacionales los roles de educador y educandos están en una distinta jerarquía, otorgando a los primeros facultades disciplinarias respecto de los alumnos, debiendo estos mantener disciplina y obediencia, las cuales de no respetarse hacen perder fuerza a todo el proyecto educativo" 8

A modo de conclusión, conviene destacar también el fallo de Delgado Maldonado, Elsa Ruth con Colegio Franciscano María Elena (2003), en el cual se recogen ambas argumentaciones analizadas en el presente capítulo. De esta forma, frente a la impugnación de una sanción disciplinaria, la Corte Suprema señaló que "el debido proceso no puede ser más lejano a la situación que se resuelve. En efecto, el artículo 20 de la Constitución Política de la República protege la garantía del numero 3 inciso $4^{\circ}$ del artículo 19, que impide ser juzgado por comisiones especiales, y, como surge claramente de su tenor y del contexto del numero en cuestión, se refiere a problemas de orden judicial o disciplinarias, dentro del que no tiene ninguna cabida el presente" .

En contra.

Contrario a lo que se ha venido analizando, y sin perjuicio con lo que se estudiará en el siguiente capítulo, en Ibarra Catalán, Mario con Escuela de Arte de la Municipalidad de Valparaíso (1982), citado precedentemente, el abogado integrante Gonzalo Calvo, sostuvo en su voto de minoría del fallo de la Corte de Apelaciones de Valparaíso, que, respecto de las sanciones disciplinarias, "no obsta a que la medida haya emanado de la actuación de un organismo que no ejerza jurisdicción, ya que el texto constitucional alude genéricamente a actos $u$ omisiones arbitrarios o ilegales, sin exigir que ellos tengan origen en un juez o tribunal, bastando por ello que su autor sea una persona o funcionario o el representante o jefe de un órgano estatal"10.

La misma opinión contraria fue sostenida recientemente por la Corte de Apelaciones de Santiago en Sepúlveda Soto, Sergio con Alcalde de la Municipalidad Providencia y Liceo José Victorino Lastarria (2007): "En el apartado $3^{\circ}$ inciso quinto del consabido artículo 19 de la Carta Fundamental se aplica, extensivamente, a todo procedimiento, aún a uno de carácter no jurisdiccional, cuanto más cuando conducente a la imposición de alguna clase de privación"1 1 .

\footnotetext{
${ }^{8}$ Matías Ignacio Salcedo Pino con Establecimiento Educacional Instituto Claret de Temuco (2005), considerando $4^{\circ}$ del fallo de la Corte de Apelaciones de Temuco.

${ }^{9}$ Delgado Maldonado, Elsa Ruth con Colegio Franciscano María Elena (2003), considerando $10^{\circ}$ del fallo de la Corte Suprema.

10 Ibarra Catalán, Mario con Escuela de Arte de la Municipalidad de Valparaiso (1982), considerando $3^{\circ}$ del voto de minoría del fallo de la Corte de Apelaciones de Valparaíso.

${ }^{11}$ Sepúlveda Soto, Sergio con Alcalde de la Municipalidad Providencia y Liceo José Victorino Lastarria (2007), considerando $15^{\circ}$ del fallo de la Corte de Apelaciones de Santiago.
} 


\section{JURISPRUDENCIA QUE SOSTIENE LA PROCEDENCIA DE LA GARANTÍA CONSTITUCIONAL DEL DEBIDO PROCESO EN LOS PROCEDIMIENTOS SANCIONATORIOS SEGUIDOS POR LOS ESTABLECIMIENTOS EDUCACIONALES}

Como se analizará a continuación, existe una abundante jurisprudencia que ha reconocido la validez y aplicación de la garantía constitucional del debido proceso en los procedimientos seguidos por los establecimientos educacionales en la imposición de sanciones disciplinarias.

\section{1) DEBIDO PROCESO Y ARBITRARIEDAD DE LAS SANCIONES DISCIPLINARIAS}

Entre los primeros fallos que tomaron en cuenta las normas de un debido proceso en los procedimientos sancionatorios aplicados por un establecimiento educacional, destacan Olivos Marín, Oriana, con Vicerrector Académico de la Universidad de Santiago (1982) y Bernardo Espinoza Bancalari a favor de Alejandro Navarro Brain y otros estudiantes con Rector de la Universidad de Concepción, don Carlos von Plessing Baentsch (1988). En ambos casos, las respectivas Cortes de Apelaciones, luego de hacer un detallado análisis de las omisiones que se cometieron en los procedimientos aplicados por los recurridos para imponer las sanciones impugnadas, acogieron los respectivos recursos de protección interpuesto por los alumnos afectados, fundado en que, como consecuencia de estas omisiones, se habría procedido en forma arbitraria en la aplicación de las referidas sanciones ${ }^{12}$. De esta forma, en Olivos Marín, Oriana, con Vicerrector Académico de la Universidad de Santiago la Corte señaló que "consta que la recurrente se le notificó por carta certificada la resolución $N^{o} 1.895$ de fs. 5, en la cual ni siquiera se señala cuáles fueron los actos constitutivos de faltas muy graves por las cuales se la sanciona; y si a ello se agrega que no se le interrogó ni se puso en su conocimiento los cargos que se le hacian, hay que concluir que se ha procedido arbitrariamente al aplicarle una medida disciplinaria a Oriana Isabel Olivos sin oirla e ignorando esta los cargos que existían en su contra"13. Por su parte, en Bernardo Espinoza Bancalari a favor de Alejandro Navarro Brain y otros estudiantes con Rector de la Universidad de Concepción, don Carlos von Plessing Baentsch la Corte concluyó que "es evidente que la forma en que el decreto impugnado se da por establecida la participación de los estudiantes mencionados como instigadores, promotores y/o ejecutores de los actos de violencia de que se trata, no es justa, ni racional, y por lo tanto, resulta arbitraria"14.

\footnotetext{
12 Es importante precisar que en ambos casos los fallos no explican de qué forma estas omisiones afectaron la garantía constitucional del debido proceso, sin ni siquiera hacer una referencia explícita a dicha garantía constitucional, sino que solamente se limitan a señalar que estas omisiones insiden en un actuar arbitrario por parte de la recurrida.

13 Olivos Marín, Oriana con Vicerrector Académico de la Universidad de Santiago (1982), considerando $4^{\circ}$ del fallo de la Corte de Apelaciones de Santiago.

14 Bernardo Espinoza Bancalari a favor de Alejandro Navarro Brain y otros estudiantes con Rector de la Universidad de Concepción, don Carlos von Plessing Baentsch (1988), considerando $14^{\circ}$ de la Corte de Apelaciones de Concepción.
} 
Junto con lo anterior, como un primer antecedente de lo que más adelante va a constituir el eje central de la jurisprudencia sobre el debido proceso en esta materia, se puede citar el fallo de Lobos Sandoval, Oscar con Rector de la Universidad de Antofagasta (1983), donde la Corte de Apelaciones de Antofagasta, al momento de analizar el recurso de protección, estimó que "para desvirtuar los reparos hechos por el recurrente a la resolución impugnada, es previo analizar si ella ha sido dictada por la autoridad correspondiente, si esta lo ha hecho dentro del ámbito de sus atribuciones y conforme a un procedimiento establecido con antelación y si la medida guarda proporción con los fundamentos de hecho que la han motivado"15.

Asimismo, en Martín Donoso Villaseñor con Subdirector Ejecutivo del Instituto Nacional de Capacitación Profesional (Inacap) (1989), la Corte de Apelaciones de Santiago, luego de un riguroso examen del procedimiento sancionatorio contemplado en el Reglamento interno del recurrido, concluyó que "no obstante la existencia de las Reglamentaciones aludidas en el fundamento que antecede, lo cierto es que en el presente caso no resulta que el Subdirector Ejecutivo de Inacap, recurrido por estos autos, les haya dado aplicación, habiéndose limitado, simplemente, a aplicar una sanción de expulsión sin otorgar ninguna oportunidad de defensa al afectado, castigo que aparece asi como arbitrario e ilegal afectando derechos constitucionalmente amparados. Es un principio fundamental de antigua data el de que 'nadie puede ser sancionado sin ser oído'. Basta recordar que Dios mismo interrogó a Adán, a Eva y a Cain antes de castigarlos"16.

\section{2) Debido proceso y Reglamento SANCiOnAtorio DE LOS ESTABLECIMIENTOS EDUCACIONALES.}

Relevante para este estudio es el fallo de Arroyo Thoms, Tamara y otras con Director de Liceo de Niñas (2001). Aquí los recurrentes impugnaron la medida disciplinaria adoptada por el establecimiento educacional, consistente en la expulsión y cancelación de la matrícula escolar, reclamando, entre otras alegaciones, que esta sanción fue adoptada sin que se hubiera realizado una investigación y sin que se hubieran escuchado descargos o explicaciones por parte de las alumnas sancionadas. La Corte de Apelaciones de Puerto Montt, acogiendo el recurso de protección, estimó, respecto del procedimiento seguido por el recurrido, que "no se han observado las normas minimas de un debido proceso, actuando en contravención al propio Reglamento Interno que rige las relaciones entre el establecimiento y los alumnos, en el cual no se encuentra contemplada especificamente la falta cuya comisión se atribuye a las sancionadas", lo que significó un actuar "en forma voluntariosa y con abierta infracción a las normas del debido proceso de ley exigido por nuestra Constitución, afectando gravemente los derechos fundamentales de las recurrentes"17.

\footnotetext{
15 Lobos Sandoval, Oscar con Rector de la Universidad de Antofagasta (1983), considerando $18^{\circ}$ de la Corte de Apelaciones de Antofagasta.

16 Martín Donoso Villaseñor con Subdirector Ejecutivo del Instituto Nacional de Capacitación Profesional (Inacap) (1989), considerando $9^{\circ}$ de la Corte de Apelaciones de Santiago.

17 Arroyo Thoms, Tamara y otras con Director de Liceo de Niñas (2001), considerandos $6^{\circ}$ y $8^{\circ}$ del fallo de la Corte de Apelaciones de Puerto Montt.
} 
Importa destacar este fallo porque en él se hacen una serie de consideraciones en orden a establecer en forma imperativa que los reglamentos internos de carácter sancionatorios de un establecimiento educacional deben recoger las normas de un debido proceso. De esta forma, señala que la aplicación de sanciones disciplinarias por parte de un establecimiento educacional deben realizarse "con sujeción al propio reglamento $y$ dando cumplimiento formal a cada uno de los pasos que alli se señalan, ya que la existencia de un reglamento 'per se' no lo hace incontrovertible, por el contrario, lo supedita a las normas legales y constitucionales, debiendo reunir los requisitos que se exigen para todo cuerpo normativo sancionatorio, esto es, que recoja normas mínimas de un debido proceso"18. Asimismo, respecto del ejercicio de las potestades disciplinarias, vuelve a reiterar que “(...) la potestad disciplinaria de los diversos entes, que ha sido estimada como un verdadero derecho penal de carácter administrativo, debe ejercerse con sujeción a las normas de un debido proceso, con pleno resguardo de los derechos esenciales que emanan de la naturaleza humana, en este caso doblemente resguardados respecto a las recurrentes, tanto por las normas pertinentes del artículo 19 de nuestra Constitución Politica, como de la Convención sobre Derechos del Niño, que en virtud del artículo $5^{\circ}$ de la misma Carta Fundamental, tienen idéntico valor, constituyéndose en limitaciones al ejercicio de la soberanía del Estado, y por ende a la potestad sancionatoria de sus organismos y de los grupos intermedios a través de los cuales se organiza y se estructura la sociedad"19.

Esta misma reflexión se encuentra también en Canales Araya, Gonzalo con Liceo José Victorino Lastarria, Inspector General don Sergio Román Rozas y Cabezas (2003). En este caso la Corte de Apelaciones de Santiago sostuvo que la aplicación de un procedimiento "racional y justo" debe existir aun cuando el Reglamento respectivo no contemple un procedimiento al respecto: "Cualquiera sea la falta que se pueda imputar a algún alumno, las medidas disciplinarias en un establecimiento educacional como el de los recurridos, debe imponerse después de algún procedimiento de investigación en el que los derechos de los menores sean rigurosamente respetados; en particular, deben ser tratados en forma digna y con total consideración y respeto", señalando acto seguido que, respecto del caso particular, "si bien en el referido Reglamento de Disciplina no se señala el procedimiento para investigar las faltas a los deberes escolares que acometan los alumnos, ni tampoco se establece una escala de sanciones, puede concluirse que el procedimiento que utilizaron los funcionarios y autoridades del Liceo (...), constituyen un acto arbitrario", concluyendo que "la arbitrariedad queda demostrada, por una parte, al constatar la falta de un procedimiento racional y justo para determinar una falta a los deberes escolares; $y$, de otra parte, por la aplicación de una sanción totalmente desproporcionada" 20 .

En esta misma dirección apunta también lo sostenido por la Corte de Apelaciones de Talca en Herminia Bobadilla Ponce con Delegado del Rector de la Universidad de Talca (1988): “(...) cabe señalar que aun cuando el artículo 20 de la Ordenanza sobre Conducta

\footnotetext{
${ }^{18}$ Considerando $4^{\circ}$.

19 Considerando $5^{\circ}$.

20 Canales Araya, Gonzalo con Liceo José Victorino Lastarria, Inspector General don Sergio Román Rozas y Cabezas (2003), considerandos $5^{\circ}$ y $6^{\circ}$ del fallo de la Corte de Apelaciones de Santiago.
} 
Revista Chilena de Derecho, vol. 36 Nº 1, pp. 165 - 184 [2009]

Matte IzQuierdo, Arturo " "Recurso de protección y garantía constitucional del debido proceso..."

Estudiantil establece que la resolución del Rector o su delegado, en su caso, es apelable ante la Junta Directiva, en dicha disposición no se señala un plazo preciso y determinado para deducir dicho recurso, ni un tiempo dentro del cual corresponda su conocimiento, con lo cual su ejercicio resulta impreciso y contrario a derecho, lo cual hace aun más necesario y procedente el recurso que se ha intentado" 21 .

En contra.

Contrarios a esta jurisprudencia, sin embargo, se muestra el fallo Fernández Fernández, Álvaro con Vicerrector Académico de la Universidad de Santiago (1983). En ese caso, el alumno fue expulsado por haber participado, al interior del recinto universitario, en una serie de actos y movilizaciones no autorizadas, frente a lo cual interpuso un recurso de protección impugnando dicha medida disciplinaria. La Corte de Apelaciones de Santiago rechazó el recurso de protección por una serie de consideraciones que no vienen al caso explicar, pero frente a la constatación de que el procedimiento aplicado conforme al reglamento interno no se ajustaba a un debido proceso, la Corte señaló lo siguiente: "No puede dejar de anotarse que en el aludido Reglamento se observa un notorio vacio en lo referente a la forma como deben establecerse los hechos que posteriormente se calificarán, estableciéndose al efecto algún tipo de procedimiento que otorgue oportunidades de intervención y defensa a quien pueda resultar afectado por la resolución que en definitiva se dicte. Es un principio fundamental de antigua data el de que 'nadie puede ser sancionado sin ser oído'. Basta recordar que Dios mismo interrogó a Adán y a Eva antes de castigarlos. En el presente caso no aparece de los antecedentes que se haya dado cumplimiento a tal elemental principio, pero esta circunstancia suscita cuestiones diversas a las que ha sido preciso fundamento del recurso intentado a fs. 1 "22.

De los fundamentos del fallo recién citado no queda claro si la razón por la cual se desestimó los vicios constatados en el procedimiento se debieron a que el recurrente no invocó la respectiva garantía constitucional del debido proceso, como efectivamente ocurrió, o porque la Corte estimó que dicha garantía no es aplicable para este tipo de situaciones. Del tenor del considerando antes trascrito da la impresión que fue la no invocación de la garantía del debido proceso lo que motivó el rechazo del recurso de protección ${ }^{23}$. Sin embargo, la constatación por parte de la Corte en cuanto a que la

${ }^{21}$ Herminia Bobadilla Ponce con Delegado del Rector de la Universidad de Talca (1988), considerando $22^{\circ}$ del fallo de la Corte de Apelaciones de Talca.

${ }^{22}$ Fernández Fernández, Álvaro con Vicerrector Académico de la Universidad de Santiago (1983), considerando $13^{\circ}$ del fallo de la Corte de Apelaciones de Santiago.

$23 \mathrm{Al}$ respecto, contrario a esta jurisprudencia, numerosos recursos de protección en materia de sanciones disciplinarias adoptadas por un establecimiento educacional han sido acogidos por nuestros Tribunales, estimando vulneradas garantías constitucionales que no fueron invocadas por el recurrente en su recurso. Los más recientes se encuentran en Müller Reyes, Carlos con Rector Colegio Alemán de Valparaíso (1995), Corte de Apelaciones de Valparaíso, 9 de marzo de 1995, Rol No 641-1994, confirmado por la Corte Suprema el 17 de mayo de 1995, Rol No 24.665-1995; Aguilar Saldaño, Diego con Directora Colegio Yangtsé y otro (1996), Corte de Apelaciones de Santiago, 23 de enero de 1996, Rol No 2.091-1996, confirmado por la Corte Suprema el 11 de diciembre de 1996, Rol No 3.343-1996; en Miguel Ariel Castillo Apolunio con Juan Antonio Rock Tarud, Rector Subrogante de la Universidad de Talca (1996), Corte de Apelaciones de Talca, 28 de octubre de 1996, Rol No 52.485-1996, confirmado por la Corte Suprema el 2 de julio de 1997, Rol No 4.203-1996; en Andrade C., Luisa, Mansilla R., José y otra con Director Liceo 
actuación impugnada no es ilegal ni arbitraria "toda vez que la autoridad que la dictó se limitó a hacer uso de facultades que le corresponden y para un caso previsto en la reglamentación respectiva" ${ }^{24}$, deja entrever de que, sin perjuicio de la omisión del recurrente al momento de fundamentar su recurso, conforme a lo indicado precedentemente, para este Tribunal no es imperativo que el reglamento interno de un establecimiento educacional cumpla con las normas de un debido proceso, según ha establecido la jurisprudencia antes analizada en este capítulo.

Una reflexión similar se hace en Juan Pablo Valdenegro Espinoza con Decano de Medicina de la Universidad de Valparaiso (2000). Frente a la suspensión de su calidad de alumno, el recurrente impugnó dicha sanción como ilegal "puesto que no fue oído, ni se investiga a través de un procedimiento formal y establecido". Sin embargo, la Corte de Apelaciones de Valparaíso rechazó el recurso de protección, y en cuanto a las alegaciones aquí invocadas, se limitó a señalar que, conforme al respectivo reglamento "los requisitos que el recurrente estima omitidos los exige la citada disposición únicamente para poner término a la condición de alumno, pero no para decidir la mera suspensión de tal calidad", razón por la cual "la actuación del Decano recurrido no puede estimarse ilegal"; sin pronunciarse respecto de si el procedimiento seguido conforme a dicha reglamentación cumplía con las normas de un debido proceso tal como lo sostuvo el recurrente ${ }^{25}$.

\section{3) DEBIDO PROCESO Y SU ÁMBITO DE APLICACIÓN EN LOS PROCEDIMIENTOS SANCIONATORIOS SEGUIDOS POR LOS ESTABLECIMIENTOS EDUCACIONALES}

De los fallos Manuel Jiménez Rojas con Rector Subrogante de la Universidad de Concepción (1998) y Juan Matus Valencia con Universidad de Valparaíso (1999) se desprende que el debido proceso debe respetarse en la adopción de todo tipo de sanciones, y no solo respecto de sanciones disciplinarias aplicadas contra alumnos, como se ha venido estudiando en el presente trabajo.

De esta forma, en Manuel Jiménez Rojas con Rector Subrogante de la Universidad de Concepción, frente a la expulsión de un profesor, la Corte Suprema señaló lo siguiente: "Que tales antecedentes constituyen mérito bastante para estimar que la investigación y posterior terminación del contrato de trabajo del profesor Manuel Jiménez Rojas, importa un acto arbitrario, desde el momento que la sanción estaba acordada desde antes que ella se realizara. Investigación que también es ilegal, en atención a que no se ha dictado el regla-

Politécnico Salesiano (1996), Corte de Apelaciones de Puerto Montt, 15 de octubre de 1996, Rol No 1.4071996, confirmado por la Corte Suprema el 24 de junio de 1997, Rol No 4.033-1996; en Eliana Maccarini Rayo, Presidente de la Junta de Vecinos No 98 de la Octava Agrupación de la Comuna de Santiago con María Díaz Martínez, Directora del Colegio Municipal No 10 Arturo Prat Chacón (1997), Corte de Apelaciones de Santiago, 29 de abril de 1997, Rol No 1.014-1997, confirmado por la Corte Suprema el 11 de agosto de 1997, Rol No 1.430-1997; y en Lecaros Torres, Sandra con Centro de Formación Técnica AIEP S.A. (2002), Corte de Apelaciones de Talca, 3 de mayo de 2002, Rol No 60.845-2002, confirmado por la Corte Suprema el 29 de mayo de 2002, Rol No 1.692-2002.

${ }^{24}$ Considerando $12^{\circ}$.

25 Juan Pablo Valdenegro Espinoza con Decano de Medicina de la Universidad de Valparaíso (2000), considerandos $5^{\circ}$ y $7^{\circ}$ del fallo de la Corte de Apelaciones de Valparaíso. 
mento pertinente que señale su procedimiento, en especial el derecho a defensa y reclamo de la decisión adoptada, lo que posibilitó se privara de ellos al afectado, sin respetarse las más elementales garantías procesales" 26 .

Asimismo, en Juan Matus Valencia con Universidad de Valparaiso, la Corte Suprema acogió un recurso de protección que impugnaba el procedimiento seguido por la universidad recurrida en la elección de rector, señalando que la Junta Directiva de la Universidad, frente al desconocimiento de lo resuelto por el Tribunal Calificador de Elecciones, "se arrogó funciones y facultades propias del Tribunal competente en la materia, actuando, en suma, como comisión especial en un ámbito sujeto a potestades reglamentarias de un Tribunal, cuyas resoluciones ignoró", con lo cual "infringieron la igual protección de la ley en el ejercicio de los derechos que conforme al inciso cuarto del numeral $3^{\circ}$ del artículo 19 de la Carta Fundamental impide que nadie sea juzgado por comisiones especiales, sino por un tribunal que fije la ley" 27.

4) Debido proceso y la Garantía del artículo 19 No 3 DE LA COnstitución Política

Las decisiones adoptadas en los fallos hasta aquí analizados se han fundamentado en gran medida en la arbitrariedad que ha significado la adopción de sanciones disciplinarias con desconocimiento de las normas de un debido proceso, siendo tímidos, sin embargo, en invocar la garantía constitucional afectada. Por el contrario, en fallos más recientes los Tribunales han optado derechamente por enunciar la garantía constitucional del debido proceso y su vulneración o no por parte de los establecimientos educacionales ha servido de fundamento para acoger o rechazar los recursos de protección interpuesto por los alumnos afectados.

Así ocurre, por ejemplo, en María Victoria Nahuelñir González por Pavel Guiñez con Rector del Liceo Enrique Molina (2004), donde la Corte de Apelaciones de Concepción dejó constancia que "no está acreditado en autos que la sanción se haya aplicado previa una investigación que cumpla las exigencias de un debido proceso, con lo que se infringió el artículo $19 N^{o} 3$ inciso $5^{\circ}$ de la Constitución Política de la República"28. También en Gonzalo Calderón Astete con Universidad Católica de la Santísima Concepción (2004), la Corte de Apelaciones de Concepción, acogiendo el recurso de protección, estimó que la actuación del recurrido contravino el artículo 19 No 3, inciso 4 de la Constitución Política ${ }^{29}$.

Esta jurisprudencia se ve reforzada por numerosos fallos que han rechazado recursos de protección justamente por estimar que la aludida garantía fue respetada por el

\footnotetext{
${ }^{26}$ Manuel Jiménez Rojas con Rector Subrogante de la Universidad de Concepción (1998), considerando $9^{\circ}$ del fallo de la Corte de Apelaciones de Concepción.

27 Juan Matus Valencia con Universidad de Valparaiso (1999), considerando $25^{\circ}$ del fallo de la Corte de Apelaciones de Valparaíso.

28 María Victoria Nahuelñir González por Pavel Guiñez con Rector del Liceo Enrique Molina (2004), considerando $5^{\circ}$ del fallo de la Corte de Apelaciones de Concepción.

${ }^{29}$ Gonzalo Calderón Astete con Universidad Católica de la Santísima Concepción (2004), considerando $5^{\circ}$ del fallo de la Corte de Apelaciones de Concepción.
} 
establecimiento educacional, con lo cual los Tribunales reconocen implícitamente la validez y aplicación para estos casos de dicha garantía constitucional y de su protección mediante esta acción cautelar.

Así ocurrió, por ejemplo, en Roberto Riquelme Maturana y Alicia Maturana Cepeda con Universidad de Viña del Mar (1994), donde la Corte de Apelaciones de Valparaíso declaró inadmisible el recurso de protección porque estimó, entre otras consideraciones, que la sanción adoptada por el recurrido fue dictada conforme "al principio constitucional de haberse dictado en un proceso previo tramitado ciñéndose a las garantías de un racional y justo procedimiento" 30 .

Lo mismo ocurrió en Marcos Salinas Figueroa con Universidad Playa Ancha (2004) al rechazarse el recurso de protección: "Que de los antecedentes de autos, se constata que la Universidad de la cual era estudiante el recurrente, realizó una investigación administrativa, en la cual se le imputaron actos que constituyen faltas estimadas como gravisimas en el Reglamento de Estudiantes, la que se ajustó en lo esencial a las reglas minimas del debido proceso, otorgándosele la oportunidad de efectuar descargos frente a imputaciones conocidas y precisas, rendir prueba, entablar recursos, encontrándose la sanción aplicada contemplada para el caso aludido en el Reglamento" 31.

Lo anterior también aparece en Valenzuela Ricci, Jorge con Sociedad del Colegio Alemán de Santiago (2008), en virtud del cual, frente a las alegaciones del recurrente en cuanto a que el alumno habría sido sancionado por una comisión especial no contemplada en el reglamento interno, la Corte de Apelaciones de Santiago estimó que el respectivo reglamento interno "establece un mecanismo en el apartado 3, denominado Procedimientos donde señala no solo el procedimiento sino también las sanciones que pudieren afectar al alumno (...), de forma tal que existiendo un estatuto y un marco reglamentario que autoriza la procedencia y competencia procederán las sanciones previo Consejo de Profesores para la aplicación de la cancelación de la matricula y la exclusión, situación que lleva a que esta garantía también será desechada" 32 . Lo anterior es complementado por la Corte Suprema que, confirmando el fallo de primera instancia, señaló que "tampoco es posible sostener que se haya violentado el derecho a no ser juzgado por comisiones especiales, toda vez que los órganos que participaron en el procedimiento que concluyó con la decisión de cancelar la matrícula al alumno recurrente son entes disciplinarios que han actuado para analizar, proponer y decidir sanciones en el ámbito de la disciplina escolar, conforme a las reglas que los apoderados aceptan al matricular a sus hijos" 33 .

\footnotetext{
${ }^{30}$ Roberto Riquelme Maturana y Alicia Maturana Cepeda con Universidad de Viña del Mar (1994), considerando $2^{\circ}$ del fallo de la Corte de Apelaciones de Valparaíso.

31 Marcos Salinas Figueroa con Universidad Playa Ancha (2004), considerando $2^{\circ}$ del fallo de la Corte de Apelaciones de Valparaíso.

32 Valenzuela Ricci, Jorge con Sociedad del Colegio Alemán de Santiago (2008), considerando $3^{\circ}$ del fallo de la Corte de Apelaciones de Santiago.

33 Valenzuela Ricci, Jorge con Sociedad del Colegio Alemán de Santiago (2008), considerando $6^{\circ}$ del fallo de la Corte Suprema.
} 


\section{5) Debido proceso y la CONVEnCión AMERICANA SOBRE DERECHOS} HUMANOS

En Sepúlveda Soto, Sergio con Alcalde Municipalidad Providencia y Liceo José Victorino Lastarria (2007), citado anteriormente, ante la constatación de que en la imposición de la sanción impugnada "no medió procedimiento alguno", la Corte no solo entiende vulnerada la garantía constitucional del debido proceso ${ }^{34}$, sino que además el artículo 25 de la Convención Americana sobre Derechos Humanos"35: "El artículo 25 de la Convención Americana sostiene que toda persona tiene derecho a un recurso sencillo, rápido y efectivo ante los jueces o tribunales competentes, que la ampare contra actos que violen no solamente sus derechos fundamentales reconocidos por la Constitución nacional sino, también, por esa Convención, aun cuando la violación sea cometida por una persona que actúa en ejercicio de sus funciones oficiales. A tal punto llega esta prevención que los Estados Partes se comprometen a garantizar que la judicatura competente decidirá sobre los derechos de toda persona que interponga este recurso, así como a que las autoridades cumplirán lo que en él se decida. En virtud del inciso segundo del artículo 5 de la Constitución Política de la República, ese artículo 25 es vinculante para los tribunales chilenos, motivo por el que la Corte también considera que se infringió la garantía del citado artículo $19 N^{\circ} 3$ inciso quinto"36.

\section{6) DEBIDO PROCESO Y LOS ELEMENTOS QUE LO CONSTITUYEN}

Numerosos fallos se han preocupado de definir el concepto de debido proceso y enumerar los elementos y etapas que deben cumplir los procedimientos sancionatorios seguidos por los establecimientos educacionales.

Así ocurrió en forma muy temprana en Olivos Marín, Oriana, con Vicerrector Académico de la Universidad de Santiago (1982), ya citado en este trabajo, donde la Corte de Apelaciones de Santiago fue clara en sostener que "los antecedentes reseñados no pueden estimarse como un sumario de tipo interno con un minimo de formalidades para que revista la calidad e imparcialidad necesarias para la aplicación de una medida tan grave como es la expulsión. En efecto, no hubo una persona encargada de establecer los hechos y tanto es asi que ni siquiera aparece que se hayan puesto en conocimiento de la alumna las infracciones que se le imputaban, dándole oportunidad de presentar sus descargos, ya sea tomándole una declaración para que expusiera su versión o permitiéndole hacerlo por escrito" 37 .

En los mismos términos fue el fallo de la Corte de Apelaciones de Concepción en Bernardo Espinoza Bancalari a favor de Alejandro Navarro Brain y otros estudiantes con

\footnotetext{
34 Ver nota al pie de página número 45.

35 La Convención Americana sobre Derechos Humanos ("Pacto de San José de Costa Rica"), fue suscrito en San José de Costa Rica el 22 de noviembre de 1969, en la Conferencia Especializada Interamericana sobre Derechos Humanos, y fue ratificada por el Congreso Nacional el 21 de agosto de 1990 y publicado en el Diario Oficial el 5 de enero de 1991.

36 Sepúlveda Soto, Sergio con Alcalde de la Municipalidad Providencia y Liceo José Victorino Lastarria (2007), considerando $15^{\circ}$ del fallo de la Corte de Apelaciones de Santiago.

37 Olivos Marín, Oriana, con Vicerrector Académico de la Universidad de Santiago (1982), considerando $3^{\circ}$ de la Corte de Apelaciones de Santiago.
} 
Rector de la Universidad de Concepción, don Carlos von Plessing Baentsch (1988): "No puede desconocerse su derecho a formular descargos y a que expusieran lo conveniente a sus defensas, puesto que el principio de que nadie puede ser juzgado sin ser oído, es uno de los pilares fundamentales de la administración de justicia"38.

En Christian Alex Salazar Allende con Universidad de Magallanes (1993), a pesar de que se estimó improcedente aplicar la garantía constitucional del debido proceso, conforme se analizó anteriormente, se señaló, sin embargo, que "para aplicar una medida disciplinaria es necesaria una investigación previa de los hechos que originan y que se haya establecido fehacientemente la responsabilidad del alumno en la falta cometida, como asimismo que se le formulen cargos al afectado y otorgado a este la oportunidad de defenderse" 39.

Más completa es la descripción que hace la Corte Suprema en Manuel Jiménez Rojas con Rector Subrrogante de la Universidad de Concepción (1998): "en la citada investigación, que se tiene a la vista, no se desarrolló defensa por el afectado Manuel Jiménez Rojas, en la que solo consta su declaración, sin que se guardaran los más elementales derechos del imputado en su tramitación, como es el de la bilateralidad de la audiencia, defensa jurídica e imparcialidad del instructor y de quien debia resolver en definitiva teniendo en consideración tales antecedentes, como tampoco se posibilitó se ejerciera por el afectado el derecho a reclamo consagrado en los Estatutos" ${ }^{40}$.

En Marcos Salinas Figueroa con Universidad Playa Ancha (2004), la Corte de Apelaciones de Valparaíso estimó que la investigación seguida por la universidad recurrida se ajustó a las normas mínimas del debido proceso, toda vez que en él se otorgó "la oportunidad de efectuar descargos frente a imputaciones conocidas y precisas, rendir prueba, entablar recursos, encontrándose la sanción aplicada contemplada para el caso aludido en el Reglamento" ${ }^{4}$.

Por su parte, en Cea Miriam con Colegio San Mateo de Osorno (2006), frente a la expulsión del alumno recurrente por faltas disciplinarias, la Corte de Apelaciones de Valdivia concluyó que "nunca hubo, hasta la comunicación del despido de 6 de abril, una oportunidad formal y un plazo adecuado para la defensa del alumno y del derecho de sus padres. Incluso la expulsión misma resultó de facto, después que la Comisión diera su mero parecer. Se castigó por una falta no descrita en el régimen disciplinario del Colegio ni calificada alli de gravísima (...)", destacando mas adelante que "es de derecho elemental

38 Bernardo Espinoza Bancalari a favor de Alejandro Navarro Brain y otros estudiantes con Rector de la Universidad de Concepción, don Carlos von Plessing Baentsch (1988), considerando $18^{\circ}$ del fallo de la Corte de Apelaciones de Concepción.

39 Christian Alex Salazar Allende con Universidad de Magallanes (1993), considerando $10^{\circ}$ de la Corte de Apelaciones de Punta Arenas. Otros fallos que destacan la necesidad de que los procedimientos sancionatorios de un establecimiento educacional garanticen el derecho a defensa del alumno sancionado se encuentran en Fernández Fernández, Alvaro con Vicerrector Académico de la Universidad de Santiago (1983), y en Martín Donoso Villaseñor con Subdirector Ejecutivo del Instituto Nacional de Capacitación Profesional (Inacap) (1989), ambos citados anteriormente en este capítulo.

40 Manuel Jiménez Rojas con Rector Subrogante de la Universidad de Concepción (1998), considerando $8^{\circ}$ del fallo de la Corte de Apeaciones de Concepción.

41 Marcos Salinas Figueroa con Universidad Playa Ancha (2004), considerando $2^{\circ}$ del fallo de la Corte de Apelaciones de Valparaíso. 
que los involucrados en un conflicto tengan un tribunal común e independiente, que establezca los hechos, que acuse, que de oportunidad de defensa, que resuelva con fundamentos y que se contemple un grado superior de apelación" 42.

En González Dominguez, José con Redland School (2006), la Corte de Apelaciones de Santiago acogió el recurso de protección, entre otras consideraciones, fundado en que la sanción impugnada "se aplicó sin atenerse, por lo menos, al elemental e inexcusable procedimiento de dar a conocer previamente al padre o madre del menor afectado, que son sus apoderados, cada uno de los cargos que se formulaban al alumno, cómo se encontraban acreditados, tanto en cuanto al hecho imputado como a la participación que el menor pudo tener en ello; privando así, no solo al alumno sancionado sino que a su familia, del legítimo derecho de defensa frente a tan graves imputaciones y sanciones" 43 .

En el mismo sentido en Tastets Torres Noelia y otros con Directora del Liceo $N^{o} 1$ Javiera Carrera (2006), donde, refiriéndose al actuar de la recurrido, la Corte de Apelaciones de Santiago hizo la siguiente reflexión: "(...) al adoptar su decisión se apartó de la legalidad, en la medida que no se sujetó a procedimiento alguno que permitiera a las afectadas exponer sus defensas, ni les dio a conocer los antecedentes justificativos de la sanción impuesta. Es de la esencia del derecho sancionatorio no solamente escuchar a la persona a la que supuestamente ha de afectar sino que se determine con precisión el comportamiento que se le reprocha y que este se encuentre de antemano reprimido" 44 .

Finalmente, destaca también la descripción que hace la Corte de Apelaciones de Santiago en Sepúlveda Soto, Sergio con Alcalde Municipalidad Providencia y Liceo José Victorino Lastarria (2007), en el que constata que las sanciones contra los alumnos recurrentes se adoptaron "sin que en un procedimiento se establezcan esos comportamientos, se los vincule directa, inmediata y causalmente a los afectados, se los impute o acuse a través de un acto minimamente formal, se los oiga, se los notifique de la sanción y se les permita la revisión por instancia distinta a la castigadora" ${ }^{45}$. Lo anterior fue expresamente ratificado por la Corte Suprema en su fallo confirmatorio al señalar que "como se dejó asentado en el fallo del tribunal a quo, en el fundamento decimotercero, habiendo participado un numero indeterminado de alumnos en los actos de ocupación de que se trata, se decidió sancionar solo a una minoría, sin que se hubiese determinado en forma

42 Cea, Miriam con Colegio San Mateo de Osorno (2006), considerando $18^{\circ}$ del fallo de la Corte de Apelaciones de Valdivia.

43 González Dominguez, José con Redland School (2006), considerando $3^{\circ}$ del fallo de la Corte de Apelaciones de Santiago.

44 Tastets Torres, Noelia y otros con Directora Liceo No 1 Javiera Carrera (2006), considerando $13^{\circ}$ del fallo de la Corte de Apelaciones de Santiago.

45 Sepúlveda Soto, Sergio con Alcalde de la Municipalidad Providencia y Liceo José Victorino Lastarria (2007), considerando $9^{\circ}$ de la Corte de Apelaciones de Santiago. Otros fallos que se han pronunciado específicamente sobre la necesidad de que la conducta sancionada y su respectiva sanción se encuentren "tipificada" en el reglamento disciplinario de los establecimientos educacionales, se encuentran en Arroyo Thoms, Tamara y otras con Director de Liceo de Niñas (2001), en Canales Araya, Gonzalo con Liceo José Victorino Lastarria, Inspector General don Sergio Román Rozas y Cabezas (2003), y en Valenzuela Ricci, Jorge con Sociedad del Colegio Alemán de Santiago (2008), todos citados anteriormente en este capítulo. 
previa, ni conste de los antecedentes, el grado de participación que en los mismos a cada uno le cupo que ameritara tal sanción" 46.

\section{ALGUNAS CONCLUSIONES}

Del estudio realizado en este trabajo aparece con claridad que es posible distinguir dos posturas irreconciliables en nuestra jurisprudencia en lo que se refiere a la vigencia y aplicación de la garantía constitucional del debido proceso en los procedimientos sancionatorios seguidos por los establecimientos educacionales, divergencia que se mantiene hasta esta fecha.

De esta forma, por un lado, se encuentra aquella jurisprudencia más bien formalista que sostiene que, por razones de texto, la Constitución Política no autoriza amparar, mediante el recurso de protección, la garantía del debido proceso frente a las omisiones cometidas por un establecimiento educacional en el procedimiento sancionatorio seguido contra un alumno. Por otra parte, se encuentra aquella jurisprudencia más garantista que reconoce la plena aplicación de esta garantía constitucional en estos procedimientos sancionatorios, y su consiguiente amparo por el recurso de protección.

Sin perjuicio del conflicto antes anotado, del conjunto de fallos estudiados que admiten la aplicación de las normas del debido proceso, se puede concluir que, conforme a la jurisprudencia estudiada, los siguientes son los elementes y las etapas que en materia de sanciones disciplinarias configuran un debido proceso, elementos que deben estar presentes en todo procedimiento sancionatorio aplicado por un establecimiento educacional, y además estar contenidos en los respectivos reglamentos sancionatorios:

a) Tipificación: que las conductas sancionadas y sus respectivas sanciones se encuentren previamente descritas en el reglamento disciplinario;

b) Instructor: presencia de un instructor imparcial encargado de establecer los faltas que se sancionan;

c) Investigación previa que establezca los hechos y las faltas sancionadas;

d) Formulación de cargos en forma precisa y fehaciente;

e) Emplazamiento: poner en conocimiento de los cargos formulados al alumno y a sus apoderados;

f) Bilateralidad de la audiencia: que el alumno tenga oportunidad de ser oído, hacer sus descargos, rendir pruebas y poder defenderse de los cargos formulados;

g) Imparcialidad de quien resuelve; y

b) Derecho a reclamo: existencia de una segunda instancia de apelación que permita revisar las sanciones adoptadas por el establecimiento educacional, debiéndose señalar un plazo para la interposición del recurso y el tiempo para su vista.

46 Considerando $5^{\circ}$. 
De esta forma, y sin perjuicio de las divergencias existentes, es posible advertir que en materia de sanciones disciplinarias adoptadas por un establecimiento educacional, nuestra jurisprudencia, en forma mayoritaria, se ha sumado a la tendencia que ha dado un amplio reconocimiento a la garantía constitucional del debido proceso.

\section{JURISPRUDENCIA CITADA}

Ibarra Catalán, Mario con Escuela de Arte de la Municipalidad de Valparaíso (1982): Corte de Apelaciones de Valparaíso, 30 de marzo de 1982 (recurso de protección), confirmado por la Corte Suprema el 20 de abril de 1982, Rol No 15.800-1982.

Olivos Marin, Oriana, con Vicerrector Académico de la Universidad de Santiago (1982): Corte de Apelaciones de Santiago, 14 de diciembre de 1982 (recurso de protección), revocado por la Corte Suprema el 26 de enero de 1983, que estuvo por rechazar el recurso de protección.

Fernández Fernández, Alvaro con Vicerrector Académico de la Universidad de Santiago (1983): Corte de Apelaciones de Santiago, 2 de mayo de 1983 (recurso de protección). Este fallo no fue apelado.

Lobos Sandoval, Oscar con Rector de la Universidad de Antofagasta (1983): Corte de Apelaciones de Antofagasta, 31 de enero de 1983 (recurso de protección), confirmado por la Corte Suprema el 15 de marzo de 1983, Rol No 1.614-1983.

Acevedo Molina, Raúl con Vicerrector Académico de la Universidad de Santiago (1984): Corte de Apelaciones de Santiago, 27 de diciembre de 1984, Rol No 237-1984 (recurso de protección), confirmado por la Corte Suprema el 11 de abril de 1985, Rol No 18.916-1985.

Bernardo Espinoza Bancalari a favor de Alejandro Navarro Brain y otros estudiantes con Rector de la Universidad de Concepción, don Carlos von Plessing Baentsch (1988): Corte de Apelaciones de Concepción, 14 de junio de 1988, Rol No 7.098-1988 (recurso de protección), confirmado por la Corte Suprema el 6 de julio de 1988, Rol No 12.7431988.

Herminia Bobadilla Ponce con Delegado del Rector de la Universidad de Talca (1988): Corte de Apelaciones de Talca, 29 de marzo de 1988, Rol No 42.514-1988 (recurso de protección), confirmado por la Corte Suprema el 14 de abril de 1988, Rol No 12.285-1988.

Martín Donoso Villaseñor con Subdirector Ejecutivo del Instituto Nacional de Capacitación Profesional (Inacap) (1989): Corte de Apelaciones de Santiago, 18 de diciembre de 1989, Rol No 481-1989 (recurso de protección). Este fallo no fue apelado.

Christian Alex Salazar Allende con Universidad de Magallanes (1993): Corte de Apelaciones de Punta Arenas, 21 de septiembre de 1993, Rol No 39-1993 (recurso de protección). Este fallo no fue apelado.

Roberto Riquelme Maturana y Alicia Maturana Cepeda con Universidad de Viña del Mar (1994): Corte de Apelaciones de Valparaíso, 5 de septiembre de 1994, Rol No 3161994 (recurso de protección), confirmado por la Corte Suprema el 29 de septiembre de 1994, Rol No 23.800-1994. 
Pedro Alberto Muñoz Betancur con Rector del Instituto Claret Teodoro Arranz San Juan (1996): Corte de Apelaciones de Temuco, 27 de noviembre de 1996, Rol No 9871996 (recurso de protección), confirmado por la Corte Suprema el 1 de julio de 1997, Rol No 4.545-1996.

Manuel Jiménez Rojas con Rector Subrogante de la Universidad de Concepción (1998): Corte de Apelaciones de Concepción, de 12 de agosto de 1998, Rol No 152-1998 (recurso de protección), revocado por la Corte Suprema el 9 de septiembre de 1998, Rol No 2.844-1998, que estuvo por acoger el recurso de protección.

Juan Matus Valencia con Universidad de Valparaiso (1999): Corte de Apelaciones de Valparaíso, 13 de noviembre de 1998, Rol No 397-1998 (recurso de protección), revocado por la Corte Suprema el 20 de enero de 1999, Rol No 4.157-1998, que estuvo por acoger el recurso de protección.

Juan Pablo Valdenegro Espinoza con Decano de Medicina de la Universidad de Valparaiso (2000): Corte de Apelaciones de Valparaíso, 17 de agosto de 2000, Rol No 436-2000 (recurso de protección), confirmado por la Corte Suprema el 14 de septiembre de 2000, Rol No 3.366-2000.

Arroyo Thoms, Tamara y otras con Director de Liceo de Niñas (2001): Corte de Apelaciones de Puerto Montt, 3 de enero de 2001, Rol No 2.840-2000 (recurso de protección), confirmado por la Corte Suprema el 23 de enero de 2001, Rol No 281-2001.

Manuel Enrique Torres Céspedes con Decano de la Facultad de Ingeniería de la Universidad Tecnológica Metropolitana (2002): Corte de Apelaciones de Santiago de 9 de octubre de 2002, Rol N 3.582-2002 (recurso de protección), confirmado por la Corte Suprema el 27 de noviembre de 2002, Rol No 4.322-2002.

Canales Araya, Gonzalo con Liceo José Victorino Lastarria, Inspector General don Sergio Román Rozas y Cabezas (2003): Corte de Apelaciones de Santiago, 17 de noviembre de 2003, Rol No 4.545-2003 (recurso de protección), confirmado por la Corte Suprema el 27 de enero de 2004, Rol No 5.426-2003.

Delgado Maldonado, Elsa Ruth con Colegio Franciscano María Elena (2003): Corte de Apelaciones de Santiago de 17 de febrero de 2003, Rol No 5.864-2002 (recurso de protección), revocado por la Corte Suprema el 8 de abril de 2003, Rol No 894-2003, que estuvo por acoger el recurso de protección.

Gonzalo Calderón Astete con Universidad Católica de la Santísima Concepción (2004): Corte de Apelaciones de Concepción, 30 de junio de 2004, Rol No 332-2004 (recurso de protección), considerando $5^{\circ}$, confirmado por la Corte Suprema el 2 de septiembre de 2004, Rol No 3.017-2004.

Marcos Salinas Figueroa con Universidad Playa Ancha (2004): Corte de Apelaciones de Valparaíso, 31 de marzo de 2004, Rol No 64-2004 (recurso de protección), confirmado por la Corte Suprema el 15 de junio de 2004, Rol No 1.304-2004.

María Victoria Nahuelñir González por Pavel Guiñez con Rector del Liceo Enrique Molina (2004): Corte de Apelaciones de Concepción, 11 de agosto de 2004, Rol No 1.3602004 (recurso de protección). Este fallo no fue apelado.

Matías Ignacio Salcedo Pino con Establecimiento Educacional Instituto Claret de Temuco (2005): Corte de Apelaciones de Temuco, 4 de mayo de 2005, Rol No 1.497-2004 
(recurso de protección), confirmado por la Corte Suprema el 1 de abril de 2005, Rol No $1.604-2005$.

Cea, Miriam con Colegio San Mateo de Osorno (2006): Corte de Apelaciones de Valdivia, 9 de junio de 2006, Rol No 351-2006 (recurso de protección). Este fallo fue apelado, pero el recurso de apelación fue declarado inadmisible por la Corte Suprema.

González Dominguez, José con Redland School (2006): Corte de Apelaciones de Santiago, 2 de octubre de 2006, Rol No 4.422-2006 (recurso de protección), revocado por la Corte Suprema el 23 de octubre de 2006, Rol No 5.439-2006, que estuvo por rechazar el recurso de protección

Tastets Torres, Noelia y otros con Directora Liceo No 1 Javiera Carrera (2006): Corte de Apelaciones de Santiago, 22 de diciembre de 2006, Rol No 5.751-2006 (recurso de protección), confirmado por la Corte Suprema el 19 de abril de 2007, Rol No 720 2007.

Sepúlveda Soto, Sergio con Alcalde de la Municipalidad Providencia y Liceo José Victorino Lastarria (2007): Corte de Apelaciones de Santiago, 19 de enero de 2007, Rol No 5.589-2006 (recurso de protección), confirmado por la Corte Suprema el 28 de mayo de 2007, Rol No 852-2007.

Valenzuela Muñoz, Sonia Margarita y otros con Director del Colegio Anexo Benjamín Vicuña Mackenna y Alcalde de la Comuna de La Florida (2007): Corte de Apelaciones de Santiago, 22 de agosto de 2007, Rol No 2.955-2007 (recurso de protección). Este fallo no fue apelado.

Valenzuela Ricci, Jorge con Sociedad del Colegio Alemán de Santiago (2008): Corte Suprema el 6 de agosto de 2008, Rol No 3.044-2008, confirmado por la Corte Suprema el 6 de agosto de 2008, Rol No 3.044-2008. 